\title{
The Empirical Analysis of the Relationship Between Sports Industry and National Economy
}

\author{
Tie Li, Cuiyu Luo, Xiaoyan Zhang \\ Department of Physical Education \\ North China Institute of Science and Technology \\ Sanhe Hebei, P.R.Chian, 101601 \\ e-mail: ncistlitie@163.com
}

\begin{abstract}
With the rapid development of sports industry in China, it has becomed the green industry in the development of national economy, and has been a new force in expanding domestic demand. This paper gives quantitative empirical analysis through the establishment of regression model, and the results show that there is a significant relationship between the development of sports industry and national economy.
\end{abstract}

Keywords- sports industry; national economy; empirical analysis

\section{INTRODUCTION}

In 2008, the United States subprime mortgage crisis breaked out, the global economy is in serious depression state, almost all national foreign trade export volume had a rapid decline. All countries have to explore the medicine for the rapid decline of economy, finally they put their hope in the domestic demands.

Sports industry is a green and low carbon one which is recognized as the sunrise industry in the world, according to the experience of western developed countries, the development of the sports industry has a huge effect on domestic demand, it is new power source for the national economic growth[1]. Since 2000, China's sports industry has rapidly developed, many scholars have studied the develop-ment of sports industry and national economy. For example, $\mathrm{Li}$ Xiaohui analysed the relationship between sports industry and national economy in view of social needs, and thought that the improvement of people's living standard had spawned more high demand for sports industry [2]. Xiao Jin thought that the Olympic Games could increase national economy, and it had indirectly an influence on national economy[3]. But the study on the relationship between sports industry and national economy mostly is of qualitative analysis, not of quantitative empirical analysis for sports industry and the national economy. In 2012, Chen Wensheng gave a quantitative empirical analysis on the economic growth in China's sports industry, he established the decom-position model, and gave the linear regression analysis[5]. Not only this paper provides the qualitative analysis, but also it tries to establish the vector autoregressive model between sports industry and national economy, and empirical analysis shows that there is the causal relationship between them, and puts forward policy suggestions according to the develop-ment of sports industry.

\section{THE RELATIONSHIP BETWEEN SPORTS INDUSTRY AND NATIONAL ECONOMY}

The development of sports industry and national economy has a very close relationship, the economic and social development decides the continuous development of sports industry, in turn sports industry plays a positive role in promoting growth of national economy.

\section{A. Improve Quality of Life and Maintain Social Stability}

Sports industry plays an important role in promoting social stability, improving the quality of life and mental outlook. Firstly, through the knowledge, skills and sports guidance to the community, sports training can effecti-vely improve the quantity and quality of sports population. At present, through the appreciation of competitive sports, participation in physical exercise, sports training has increasingly becomed the way of life of modern people. Secondly, sports are beneficial to improve the quality of workers, to improve labor productivity. The research of foreign scholars shows that if one often takes part in physical activities the labor productivity is higher by an average of $6 \%-10 \%$ than those who do not participate in sports. Finally, sports industry provides an important place of cultural activities and scientific, reasonable, healthy way of life for the community, and it can digest a large number of social leisure time, meet the needs of children and youth sports entertainment, partially solve the health problem of the elder and the disabled ones.

\section{B. Optimize Industrial Structure and Promote the Growth of National Economy}

As sports industry in the tourism and leisure industry, it has a positive effect of the total national economy. Sports industry is smokeless industry, green industry, health industry and low energy consumption, it has the industry development and potential. According to statistics, the annual output value of American sports industry amounts to 2100 billions dollars, it doubles the total income of the automobile manufacturing industry, accounting for about $2 \%$ of GDP; Sports industry contribution rate to Australian GDP is more than 1\%; In England the annual output value of the sports industry is about 70 billions pounds, the annual output value of more than automobile manufacturing industry and the tobacco industry, the government can 
receive up to 24 billions pounds from the tax every year; In Switzerland only the skiing can bring about 70 billions dollars; In China 2008 Beijing Olympic games can producce about the 20 billions dollars in direct economic income.

\section{EMPIRICAL ANALYSIS BETWEEN SPORTS INDUSTRY AND NATIONAL ECONOMY}

\section{A. Variable Selection and Data Processing}

According to the different regions of China sports national economy of industry development and regional development index as the object of study. Selected in 2009 China's Eleventh National Games in different provinces score (DF) and the 2009 sports investment quota (TZ) represents the development of local sports industry, from 2009 per capita gross domestic product (RGDP) as the development of local economy, the index data are shown in table 1. In order to eliminate the heteroscedasticity, we can deal with DF, TZ and RGDP by log processing, respectively, denoted as LNDF, LNTZ and LNRGDP.

TABLE I. STATISTICAL INDEXES RELATED TO SPORTS INDUSTRY AND THE NATIONAL ECONOMY

\begin{tabular}{|c|c|c|c|}
\hline Province & DF & TZ & RGDP \\
\hline Shandong & 2568.50 & 402.40 & 3.58 \\
\hline Guangdong & 2827.50 & 211.30 & 4.10 \\
\hline Jiangsu & 2679.00 & 142.80 & 4.46 \\
\hline Liaojing & 2568.50 & 132.10 & 3.52 \\
\hline Shanghai & 2548.25 & 62.50 & 7.83 \\
\hline Beijing & 1754.00 & 77.40 & 6.92 \\
\hline Sichuan & 1563.50 & 82.60 & 1.73 \\
\hline Zhejiang & 1515.00 & 84.30 & 4.44 \\
\hline Hbei & 1305.00 & 90.30 & 2.45 \\
\hline Heilongjiang & 1303.50 & 22.50 & 2.24 \\
\hline Tianjin & 1081.50 & 24.20 & 6.13 \\
\hline Fujian & 996.50 & 53.10 & 3.37 \\
\hline Hubei & 848.00 & 103.20 & 2.26 \\
\hline Henan & 783.00 & 149.70 & 2.05 \\
\hline Hunan & 756.50 & 79.20 & 2.04 \\
\hline \multicolumn{2}{|c|}{ Data sources: http:/www.11th-games.org.cn/. } \\
\hline r.
\end{tabular}

Data sources: http://www.11th-games.org.cn/.

TZ unit: Billion yuan; RGDP unit: Million yuan.

\section{B. Stationary Test}

Firstly, there is the stationarity test for sports scores (DF), the sports investment (TZ)and regional per capita GDP (RGDP), the test results are shown in table 2.

From table 2, ADF test shows that the original sequence values are no significant at the significant level of 5\%, which indicetes that these sequences have unit root, namely the non-stationary series; however, all of the first-order differen-tial sequence reject the unit root hypothesis exists at 5\% significant level, namely the first order difference partial sequences are stationary.
TABLE II. UNIT ROOT TEST

\begin{tabular}{|c|c|c|c|c|}
\hline Variables & ADF test & $(c, t, p)$ & $\begin{array}{c}5 \% \text { critical } \\
\text { value }\end{array}$ & Prob* $^{*}$ \\
\hline LNDF & 0.1403 & $(c, 0,2)$ & -3.0989 & 0.9569 \\
\hline DLNDF & -4.3954 & $(c, 0,2)$ & -3.1199 & 0.0056 \\
\hline LNTZ & -2.5252 & $(c, 0,2)$ & -3.0989 & 0.1307 \\
\hline DLNTZ & -3.3815 & $(c, 0,2)$ & -3.2127 & 0.0388 \\
\hline LNRGDP & -0.8950 & $(0,0,2)$ & -1.9740 & 0.3081 \\
\hline DLNRGDP & -4.7903 & $(c, 0,2)$ & -3.1449 & 0.0035 \\
\hline
\end{tabular}

\section{Cointegration Test}

Cointegration test results in table 3 show that, at the 5\% level of significance. The development of sports industry (sports scores), has a cointegration relationship between the sports investment and GDP per capita, so there is a longterm stable equilibrium relationship between each index.

TABLE III.

JOHANSEN COINTEGRATION TEST

\begin{tabular}{|c|c|c|c|c|}
\hline $\begin{array}{c}\text { Null } \\
\text { Hypothesize }\end{array}$ & Eigenvalue & Trace & $\begin{array}{c}5 \% \text { Critical } \\
\text { Value }\end{array}$ & Prob. \\
\hline None & 0.9522 & 44.49 & 29.80 & 0.0005 \\
\hline At most 1 & 0.3787 & 9.05 & 15.49 & 0.5084 \\
\hline At most 2 & 0.2976 & 3.86 & 3.84 & 0.0487 \\
\hline
\end{tabular}

\section{Granger Causality Test}

The cointegration test can only show that there is obvious relationship between these three indicators, but does not show the existence of economic meaning exactly between them, whether a causal relationship needs to be further verified. This article take the causality between Granger causality test method for inspection of each index. The test results are shown in table 4.

Granger causality test results show that:

(1) DF is Granger reason of RGDP, however RGDP is not Granger reason of DF. This shows that if the development of sports industry is better, the regional economic benefit is high, then the living standard of residents is relatively high; however, the individual regional per capita GDP is relatively high, but the development of the sports industry is not the best, which is mainly embodied in Beijing, Tianjin and Shanghai, where the tatal population is comparatively few.

(2) DF is Granger reason of TZ, and TZ is Granger reason of DF. If a regional pays attention to sports industry, more sports investment will be added, so the development of regional sports industry naturally is good; and sports industry development will drive the regional economic. These results show that the development of regional sports industry of our country is more healthy.

(3) TZ is not Granger reason of RGDP, and RGDP is Granger reason of TZ. 
TABLE IV.

GRANGER CAUSALITY TES

\begin{tabular}{|c|c|c|c|}
\hline Null Hypothesize & Obs & F-Statistic & Prob. \\
\hline $\begin{array}{c}\text { DF does not Granger } \\
\text { Cause RGDP }\end{array}$ & 13 & 3.5861 & 0.0367 \\
\hline $\begin{array}{c}\text { RGDP does not Granger } \\
\text { Cause DF }\end{array}$ & 13 & 3.6743 & 0.0314 \\
\hline $\begin{array}{c}\text { DF does not Granger } \\
\text { Cause TZ }\end{array}$ & 13 & 4.7527 & 0.0211 \\
\hline $\begin{array}{c}\text { TZ does not Granger } \\
\text { Cause DF }\end{array}$ & 13 & 4.9815 & 0.0094 \\
\hline $\begin{array}{c}\text { TZ does not Granger } \\
\text { Cause RGDP }\end{array}$ & 13 & 0.8745 & 0.7862 \\
\hline $\begin{array}{c}\text { RGDP does not Granger } \\
\text { Cause TZ }\end{array}$ & 13 & 3.1269 & 0.0463 \\
\hline
\end{tabular}

\section{POLICY SUGGESTIONS FOR THE DEVELOPMENT OF SPORTS INDUSTRY}

The empirical analysis shows that there is the Granger causal relationship between sports industry and national economy, that is to say the development of sports industry plays a positive role in promoting growth of national economy. Therefore, it is significance to the sports industry itself and the development of national economy can also promote the further development of the sports industry. The following policy suggestions are provided, hoping to have certain effect to the development of China's sports industry and national economy growth.

\section{A. Improve the Status of Sports Industry in the National Economy}

The past development of sports industry in China relies on the support of the government, some sports industry decision makers do not have a clear understanding of the role, nature and status of sports industry. For a long time sports industry economic effect had benn ignored. Although China's economy is in the stage of rapid development, with the global financial crisis in 2008, China's economic growth has slowed down, it will be impossible to completely rely on government investment to develope economy. Therefore, finding new economic point of growth and expanding domestic demand will be the new economic growth starting point. So our country must improve the important status of sports industry in national economy, must change the government's role and responsibility in the development of sports industry, must strengthen the administrative management and macro guidance.

\section{B. Open Sports Consumer Market and Improve Sports Consumption Consciousness}

Consumer demand is the driving force to promote economic growth of sports industry, it belongs to the consumption areas of the tertiary industry, thus increasing the consumption of sports industry naturally will increase consumption of the tertiary industry, then the optimization of the economic structure is of great significance to improve the quality of economic development. Moreover, with rapid development of China's economy and the improvement of people's living standard, the consumption demand of sports has greatly been improved, so that new vitality has been injected for the development of the sports industry, and it puts forward higher requirements for the development of the sports industry. Therefore, we must open sports consumer market, raise people's awareness of sports consumption. This requires us to strengthen the publicity of sports consumption and constant guide, by repeatedly strengthening people's awareness of sport consumption.

\section{ACKNOWLEDGMENT}

I would like to express my gratitude to all those who helped me during the writing of this thesis, who gave me a lot of valuable suggestions.

\section{REFERENCES}

[1] Yunfeng Jie. Study on the relationship of Sports industry development and economic growth [J]. Productivity research, 2010, 8: 19951998

[2] Xiaohui Li, Hongmin Ma. Influence of sports industry on the development of China's modern economy[J]. Enterprise economy, 2009, 6: 50-152.

[3] Tongren Jiang, Na Liu, JinLong Hou. Trend and Enlightenment of developed country sports industry evolution [J]. Journal of Wuhan Sports Institute, 2012, 46 (9): 42-49.

[4] Changjiang Liu, Hui Liu. Development strategy of sports industry in China [J]. Sports culture development, 2010, 7: 65-67.

[5] Wensheng Chen. The development of sports industry's contribution to China's economic growth [J]. Sports humanities and Sociology, 2012, 2 (19): 2-74.

[6] Tao Liu, Liang Liu. The development trend in China's sports industry research [J]. Sports culture development, 2013, 1: 78-80.

[7] Fei Yang. The subject of China's sports industry competitiveness analysis model [J]. Sports culture development, 2012, 9: 73-76.

[8] Jun Yao, Kai Huang. Government sport management transform under market economy[J]. Policy and Legal, 2008(2): 24-26.

[9] Huohui Hou. On the development of the sports leisure industry[J]. Education and Teaching Research, 2010(3): 13.

[10] Wenchang Feng. Study on the development strategies for Chinese leisure sports industry[D]. 2011 International Conference on Information, Services and Management Engineering, 2011, 924-928. 